\title{
Doing Astronomy with Small Telescopes
}

\author{
Kangujam Yugindro Singh1, Irom Ablu Meitei2, Salam Ajitkumar Singh1 \\ ${ }^{1}$ Department of Physics, Manipur University, Canchipur, Imphal, India \\ ${ }^{2}$ Department of Physics, Pettigrew College, Ukhrul, India \\ Email:yugindro361@gmail.com, ablu.irom@gmail.com
}

Received 4 September 2014; revised 3 October 2014; accepted 1 November 2014

Copyright (C) 2014 by authors and Scientific Research Publishing Inc.

This work is licensed under the Creative Commons Attribution International License (CC BY). http://creativecommons.org/licenses/by/4.0/

(c) (i) Open Access

\begin{abstract}
We are playing a lead role for growth of astronomy and its quality teaching and research in Manipur, a State located at northeast India (longitude $=93^{\circ} 58^{\prime} \mathrm{E}$; latitude $=24^{\circ} 44{ }^{\prime} \mathrm{N}$; altitude $=782 \mathrm{~m}$ ). We have innovatively designed and constructed three cost effective observatories, each costing a few hundred USD. These observatories are completely different in design and are perfectly usable for doing serious work on astronomical observation and measurements, using small ground-based telescopes. One Celestron CGE1400 telescope is housed with equatorial mounting in one of three constructed observatories and the same observatory has been inducted, since January 2012, as one of the members of the "Orion Project", which is an international project headquartered at Phoenix, Arizona, USA, dedicated for photometric and spectroscopic observations of five bright variable stars of the Orion constellation. We have been producing high precision BVRI photometric data that match well with those produced by other observatories enrolled in the Orion project. Our photometric data were presented and discussed in the 33rd Annual Conference of the Society for Astronomical Sciences: Symposium on Telescope Science, held at Ontario, California, USA during June 12 - 14, 2014. Further, we could successfully demonstrate them to the entire population of the State and play live shows of the observation of three spectacular astronomical events namely, solar eclipse of 15th January 2010, lunar eclipse of 10th December 2011 and Transit of Venus of June 6, 2012. We have conducted a number of seminars and workshops for training and research in astronomy. In the present paper, we would like describe our self-built observatories, our observational facilities, the BVRI photometric data that we acquired for the Orion project, and other activities undertaken for growth of astronomy activities in the State of Manipur, India.
\end{abstract}

\section{Keywords}

Self-Built Observatories, Orion Project, Variable Stars

\section{Introduction}

Having an observatory equipped with at least a telescope and starlight-measuring equipment such as photometer, 
CCD camera, spectrograph, etc. is first and foremost requirement for doing serious work in astronomy. We have three small telescopes (Celestron 9.25", Meade 12" and Celestron 14") and many backend telescope accessories including photometer, CCD camera, spectrograph, etc., purchased at different times during 2004 to 2012. However, because of financial constraints we could not afford to purchase commercially available ready-to-use observatories such as the Sirius observatory made in Australia, which would cost about USD 25,000 (inclusive of shipping, custom duty and other charges) on delivery at our place. To meet our requirement for housing our telescopes, we have innovatively designed three observatories and constructed them, each costing a few hundred USD. These observatories are completely different in design and are perfectly usable for doing serious work on astronomical observations and measurements. Out of the three observatories, the one which houses the Celestron 14" telescope has been put to use, since January 2012, for contributing BVRI photometric data to the international "Orion Project" headquartered at Phoenix, Arizona, USA, which is dedicated for photometric and spectroscopic observations of five bright variable stars of the Orion constellation [1]. Our photometric data were presented and discussed in the 33rd Annual Conference of the Society for Astronomical Sciences: Symposium on Telescope Science held at Ontario, California, USA during June 12-14, 2014 [2]. Our CCD cameras have been tested by taking CCD images of the Moon, Jupiter and Saturn and our spectrographs also have been tested with standard light sources. They are ready to be used as integrated components of our observatories.

Because of our strong enthusiasm and commitment for astronomy popularization and education in our State, Manipur (longitude $=93^{\circ} 58^{\prime} \mathrm{E}$; latitude $=24^{\circ} 44^{\prime} \mathrm{N}$; altitude $=782 \mathrm{~m}$ ), we could successfully demonstrate them to the entire population of the State and play live shows of the observation of three spectacular astronomical events namely, Solar eclipse of 15th January 2010, Lunar eclipse of 10th December 2011 and Transit of Venus of June 6 , 2012. Besides these, we have conducted a number of seminars and workshops for training and research in astronomy. We are also playing a lead role in the State for growth of astronomy and its quality teaching and research in the University and College sectors.

In what follows we innovatively describe our self-built observatories (in Section 2), activities for the international Orion project (in Section 3), measures taken up for astronomy education (in Section 4) and a brief conclusion (in Section5).

\section{Self-Built Observatories}

We have built three cost effective observatories in different models for housing our 3 telescopes (Celestron 9.25", Meade 12" and Celestron 14"). All of these observatories are now fully functional.

Figure 1 is the picture of a self-built dome type observatory used for housing one Celestron 9.25" telescope. This observatory was constructed in 2009 at a cost of about 700 USD. The unique feature of this observatory is that it has a hemispherical roof with a collapsible strip, which can rotate along a circular groove running on the top of the main cylindrical body. Opening the strip and rotating the dome can make the entire sky accessible to the telescope housed inside the structure. Table 1 gives the physical parameters of this observatory.

The Celestron 9.25" telescope housed in this observatory has been used, after an accurate equatorial mounting, for planetary imaging using Optec's ST7 CCD camera and for photometric observations of some variable stars

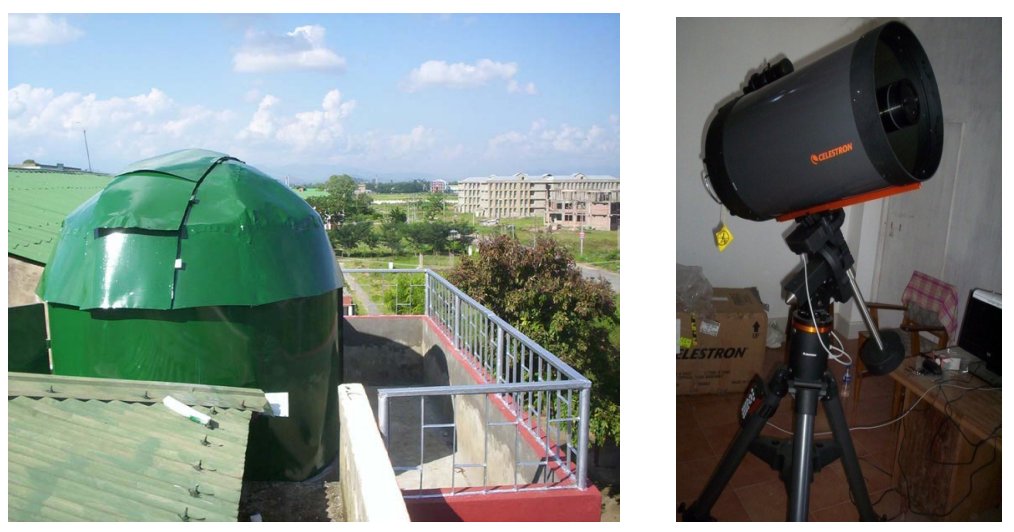

Figure 1. Picture on the left is a self-built dome-type observatory and that on the right is the in-housed Celetron 9.25" telescope. 
Table 1. Physical parameters of the dome type observatory (Figure 1).

\begin{tabular}{cc}
\hline Diameter of dome at the base & $7.5^{\prime}$ \\
Height of the cylindrical body & $4.5^{\prime}$ \\
Breadth of sky opening stripe & $1.5^{\prime}$ \\
Max dome height from the base & $7^{\prime} 3^{\prime \prime}$ \\
Area of entrance door & $4.5^{\prime} \times 2^{\prime} 10^{\prime \prime}$
\end{tabular}

using Optec's SSP3A photometer. A weakness of this observatory is that a single person cannot manage controlling both the telescope and the upper movable doom; it requires at least two persons, one for controlling the position of the movable upper doom and the other for controlling the telescope and taking observations.

Figure 2 is the picture of a self-built hut-type observatory used for housing one Celestron 14" telescope. This observatory, which was built in 2011 at a cost of just USD 200, is typically hut-type with a tin roof. It has a main entrance door. The structure as a whole is movable with 4 pairs of wheels: 2 pairs in the front and 2 pairs in the back. Keeping the main door open, the structure as a whole can be taken away from in-housed fixed telescope so that the entire sky is accessible to the telescope. Table 2 gives the physical parameters of this observatory.

The Celestron 14" telescope housed in this observatory has been in service, also after an accurate equatorial mounting, for taking photometric observation of five Orion variable stars, as a part of the international "Orion Project" described in the next section i.e., Section 3, using an Optec's SSP3 photometer. One SBIG made DSS7 coupled to an Optec's ST7 camera are going to be inducted soon for this observatory for taking part in spectroscopic observation of the five Orion stars, also as part of the Orion project. This hut-type observatory is found to be easy and convenient for taking astronomical observations; a single person can manage the whole observation session.

Figure 3 is the picture of a self-built bullet-type observatory used for housing one Meade 12" telescope. This observatory which was built in April, 2014 at a cost of about USD 200 is typically a bullet-type with a tin roof head. Its lower portion is fixed while the upper portion i.e., the tin roof head, is movable on pair of rail tracks by means 4 wheels fixed on the base foot of the roof head. It has an entrance door. By moving away the upper portion, the telescope can see the whole sky. Table 3 gives the physical parameters of this observatory.

The Meade 12" telescope housed in this observatory is permanently mounted on an equatorial wedge and it will be used for CCD photometry of some SU UMa stars i.e. a subclass of dwarf novae, for looking out their bursts, super outbursts and super humps which are characteristics of the star systems. A single person can easily control the observatory and conduct an observation session.

Though all of the three self-built observatories described above, are usable for scientific research in astronomy, the hut-type observatory shown in Figure 2 and the bullet-type observatory shown in Figure 3 are more practical in the sense that they are very cost effective and easy to operate. Therefore, the hut-type and bullet-type observatories may be good examples for all researchers including amateur astronomers who are constrained with limited budget but wish to make meaningful contribution in scientific research in astronomy, with small telescopes. Potential fields of research which can be done with small telescopes housed in such proto-type observatories include astrometry, imaging, photometry, polarimetry and spectroscopy. For producing high-precision standard data amateurs should keep in touch with global organizations such as American Association of Variable Star Observers (AAVSO), Society for Astronomical Sciences (SAS), French Association of Variable-Star Observers (AFOEV), Centre for Backyard Astrophysics (CBA), etc. Such a standard data can definitely supplement the results from large observatories and will be worthwhile for doing science in Astronomy.

\section{The international "Orion Project"}

Since January 2012, MU observatory has been participating, as the lone member from India, in the International "Orion Project” [3], headquartered at Phoenix, Arizona, USA for photometric and spectroscopic observation of five variable stars of the Orion constellation namely, Betelgeuse (alpha Orionis), Rigel (beta Orionis), Mintaka (delta Orionis), Alnilam (epsilon Orionis) and Alnitak (zeta Orionis). As on September 2, 2014, eighteen observatories across the globe (twelve from USA, one each from India, UK, France, New Zealand, Austria, Germany) 

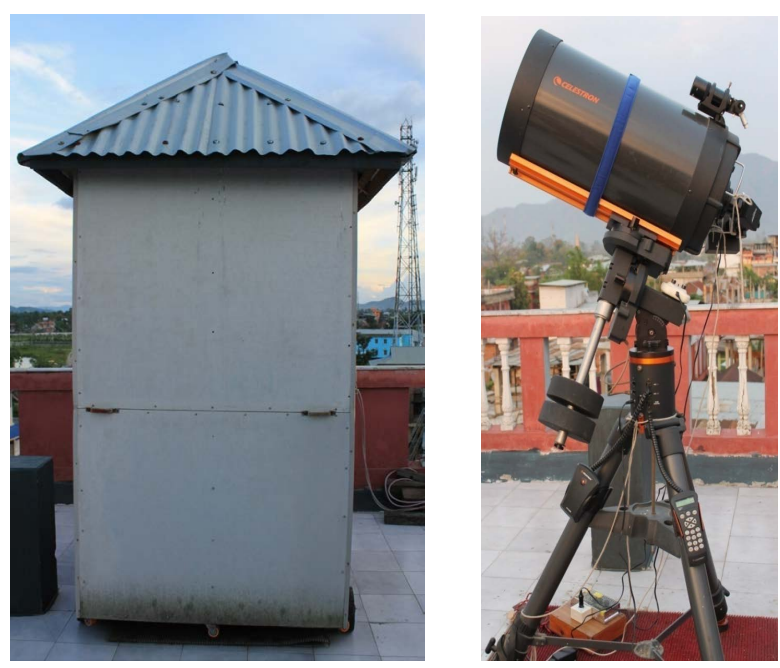

Figure 2. Self-built hut-type observatory (left) and the inhoused Celestron 14" telescope (right).
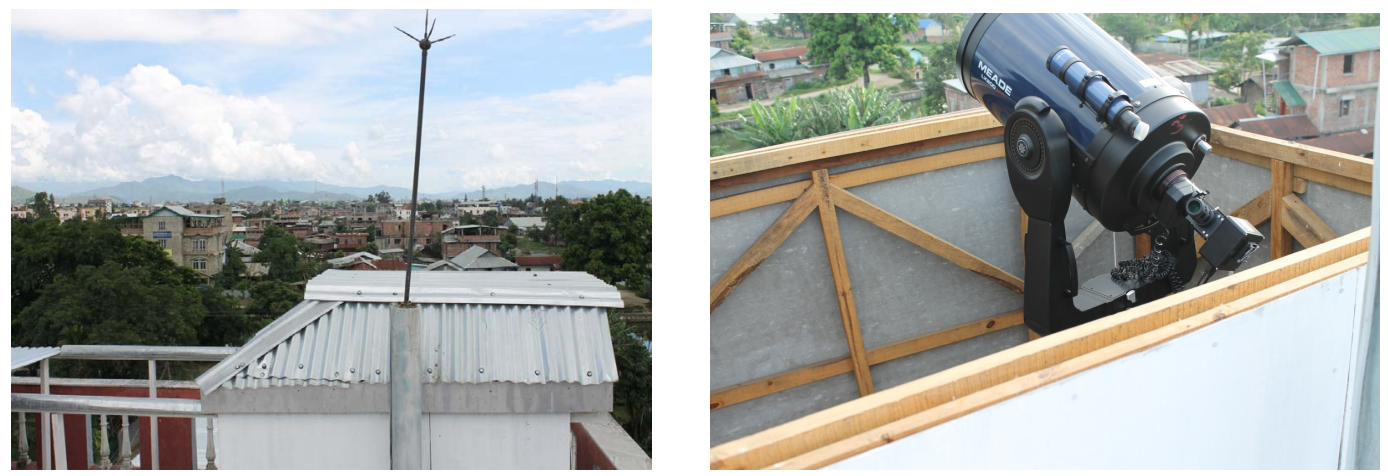

Figure 3. Self-built bullet-type observatory (left) and the in-housed Meade 12" telescope (right).

Table 2. Physical parameters of the hut-type observatory (Figure 2).

\begin{tabular}{cc}
\hline Base area of main body & $4^{\prime} 2^{\prime \prime} \times 7^{\prime}$ \\
Height of main body & $7^{\prime}$ \\
Height of roof top from the base & $9^{\prime} 6^{\prime \prime}$ \\
Area of entrance door & $4^{\prime \prime} 2^{\prime \prime} \times 7^{\prime}$ \\
\hline
\end{tabular}

Table 3. Physical parameters of the bullet-type observatory (Figure 3).

\begin{tabular}{cc}
\hline Base area of the fixed portion & $6^{\prime} 7^{\prime \prime} \times 5^{\prime} 3^{\prime \prime}$ \\
Height of the fixed portion & $5^{\prime} 1^{\prime \prime}$ \\
Height of the roof from the base & $7^{\prime} 1^{\prime \prime}$ \\
Area of entrance door & $4^{\prime} 2^{\prime \prime} \times 2^{\prime}$ \\
\hline
\end{tabular}

are taking part in the Orion project. The details of the eighteen observatories are given Table 4.

The Orion project has several goals. First goal is to help beginners with photometry and spectroscopy. The second goal is the actual observations and data acquisition. The project stems out on realising that the programstars, because of their intense brightness, are seldom observed in detail and that they pose a serious problem for observation in most professional observatories. The project speculates that by having these stars observed over a long time, interesting changes might be seen that will warrant closer investigation. The third goal 
Table 4. Observers of the Orion project.

\begin{tabular}{|c|c|c|c|c|c|c|}
\hline \multirow{2}{*}{ Observer } & OC/AAVSO & \multirow{2}{*}{ Observatory } & \multirow{2}{*}{ Location } & \multirow{2}{*}{ Telescope } & \multirow{2}{*}{ Spectrograph/Camera } & \multirow{2}{*}{ Photometer } \\
\hline & ID & & & & & \\
\hline \multirow{4}{*}{ Jeff Hopkins } & \multirow{4}{*}{$\underline{\mathrm{HPO}}$} & \multirow{4}{*}{$\begin{array}{l}\text { Hopkins Phoenix } \\
\text { Observatory }\end{array}$} & \multirow{4}{*}{$\begin{array}{c}\text { Phoenix, Arizona } \\
\text { USA }\end{array}$} & \multirow{4}{*}{$\begin{array}{l}\text { 12" LX200 GPS } \\
\text { SCT }\end{array}$} & Lhires III 2400/600 l/mm & \multirow{4}{*}{ SSP-4 } \\
\hline & & & & & ALPY 600 & \\
\hline & & & & & Star Analyser & \\
\hline & & & & & Orion Starshoot G3 & \\
\hline \multirow{3}{*}{ Gene Lucas } & \multirow{3}{*}{$\underline{\mathrm{NOAO}}$} & \multirow{3}{*}{$\begin{array}{l}\text { Night Owl } \\
\text { Astrophysical } \\
\text { Observatory }\end{array}$} & \multirow{3}{*}{$\begin{array}{c}\text { Fountain Hills, } \\
\text { Arizona USA }\end{array}$} & \multirow{3}{*}{ 10" LX200 SCT } & Star Analyser & BVRI \\
\hline & & & & & $100 \mathrm{l} / \mathrm{mm}$ & DSI Pro \\
\hline & & & & & DSI Pro & \\
\hline \multirow{2}{*}{ Joe Gianninoto } & \multirow{2}{*}{$\underline{\mathrm{DDO}}$} & \multirow{2}{*}{$\begin{array}{l}\text { Devil Dog } \\
\text { Observatory }\end{array}$} & \multirow{2}{*}{$\begin{array}{c}\text { Tucson, Arizona } \\
\text { USA }\end{array}$} & NP 127is, & Star Analyser & \multirow{2}{*}{ N/A } \\
\hline & & & & Mach AP GTO & 100 l/mm & \\
\hline \multirow[t]{2}{*}{ Laurent Corp } & \multirow[t]{2}{*}{$\underline{\text { CLZ }}$} & \multirow{2}{*}{$\begin{array}{c}\text { Garden } \\
\text { Observatory }\end{array}$} & \multirow[t]{2}{*}{ Rodez, France } & $\begin{array}{l}\text { 8" Newtonian } \\
\text { F/5.92 }\end{array}$ & \multirow{2}{*}{ N/A } & CCD ST7 \\
\hline & & & & Fork Mount & & BVRI \\
\hline $\begin{array}{l}\text { Yugindro, Singh } \\
\text { \& I. Ablu Meitei }\end{array}$ & $\underline{\mathrm{MU}}$ & $\begin{array}{l}\text { Manipur } \\
\text { University }\end{array}$ & Manipur, India & $\begin{array}{c}\text { Celestron 14 CGE } \\
1400 \text { XLT }\end{array}$ & N/A & SSP-3 BV \\
\hline Ken Sikes & $\underline{\text { SKED }}$ & Sikes Obervatory & $\begin{array}{c}\text { Chandler, } \\
\text { Arizona USA }\end{array}$ & 10" LX SCT & N/A & SSP-3a \\
\hline Jim Tubbs & $\underline{\text { TJDA }}$ & Tubbs Observatory & $\begin{array}{c}\text { Twin Falls, Idaho } \\
\text { USA }\end{array}$ & $\begin{array}{c}\text { 8" LX200 GPS } \\
\text { F/6.3 }\end{array}$ & $\begin{array}{c}\text { Star Analyser } \\
100 \mathrm{l} / \mathrm{mm}\end{array}$ & N/A \\
\hline Carl Knight & $\underline{\mathrm{KCD}}$ & $\begin{array}{l}\text { Ngileah } \\
\text { Observatory }\end{array}$ & $\begin{array}{l}\text { Bulls, New } \\
\text { Zealand }\end{array}$ & $\begin{array}{l}\text { 12" LX90 LNT } \\
\text { F/10 }\end{array}$ & N/A & SSP-4JH \\
\hline Steve Spears & $\underline{\mathrm{SSCC}}$ & $\begin{array}{c}\text { Spears } \\
\text { Observatory }\end{array}$ & $\begin{array}{c}\text { Westlake, Ohio } \\
\text { USA }\end{array}$ & & $\begin{array}{c}\text { Star Analyser } \\
100 \text { l/mm }\end{array}$ & N/A \\
\hline Phil Hoppes & $\underline{\mathrm{HPEA}}$ & $\begin{array}{l}\text { Ovegaard } \\
\text { Outreach } \\
\text { Observatory }\end{array}$ & $\begin{array}{l}\text { Overgaard, } \\
\text { Arizona USA }\end{array}$ & $\begin{array}{l}\text { 10" LX200 } \\
\text { Classic }\end{array}$ & $\begin{array}{c}\text { L200 } \\
\text { 1200/600/300 l/mm } \\
\text { Atik 314+ }\end{array}$ & UBVRc, Ic \\
\hline Steve Cuthbert & SCO & Cuthbert & York, United & Fsnirt $120 \mathrm{~mm} / 7$ & ALPY 600 & \\
\hline geve gutmotil & $\underline{\pi}$ & Observatory & Kingdom & 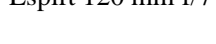 & ATIK 314L+ & \\
\hline John Menke & $\underline{\mathrm{JMO}}$ & John Menke & $\begin{array}{l}\text { Barnesville, } \\
\text { Maryland }\end{array}$ & C11. Newtonian & DSS7 & N/A \\
\hline & & & USA & & ST402, ST1603 & \\
\hline Jerry Persha & PGD & Jerry Persha & Lowell, Michigan & Meade 10" SCT & N/A & SSP-4 JH \\
\hline & & Observatory & USA & Classic, F/10 & & \\
\hline Al Stipuring & ASO & Al Stiewing & Phoenix, Arizona & 8" SCT C-8 & N/A & SSP_4 JH \\
\hline Al sulewing & $\underline{\mathrm{ASO}}$ & Observartoy & USA & 8 SU1.C-O & $\mathrm{N} / \mathrm{A}$ & $3 \triangle P-4$ Jח \\
\hline & & Austrian North & & & Star Analyser & \\
\hline Schroefl & $\underline{\text { ANO-VST }}$ & $\begin{array}{l}\text { Observatory-Very } \\
\text { Small Telescope }\end{array}$ & Vienna, Austria & 11" C-11 & $\begin{array}{c}\text { DADOS } \\
200 / 900 / 1200 \mathrm{l} / \mathrm{mm}\end{array}$ & N/A \\
\hline
\end{tabular}

of the project is to generate an excellent archive of photometric and spectroscopic data.

The authors of this paper are the observer members of MU observatory, India. A photo snap of these authors taken along with the equipment used for the Orion project is shown in Figure 4.

The photometric data obtained from MU observatory for the Orion project were presented in the 33rd Annual Conference of the Society for Astronomical Sciences: Symposium on Telescope Science, held at Ontario, California, USA during June 12-14, 2014 [4]. Meissa was used as the comparison star. The BVRI band photometry obtained by using SSP3 photometer, of the five stars of the Orion project under study namely, Betelgeuse, Rigel, 
Alnilam, Alnitak, Mintaka are shown in Figures 5-9. The data points marked with "MU” are due to MU observatory and those marked with "SKED" are due to Sikes Observatory, Arizona, USA [5].

\section{Astronomy Education}

Besides our participation in the Orion project, we have also conducted a number of programmes, using small telescopes, for popularization and education of astronomy amongst the public. We could demonstrate successfully to the entire population of the State, live shows of the observation of three spectacular astronomical events namely, Solar eclipse of 15th January 2010, Lunar eclipse of 10th December 2011 and Transit of Venus of June 6 , 2012. The observation of these events were widely publicised and covered by print and electronic media. The photo in Figure 10 shows K. Y. Singh having a live TV phone-in-iteraction program with the public on observation of the total lunar eclipse on 10th December, 2011, through a State Television Network (ISTV). A Celestron CGE925 telescope was used for observation of the total lunar eclipse.

Our observation of the Transit of Venus on June 6, 2012 was spectaculary successful as thousands of people

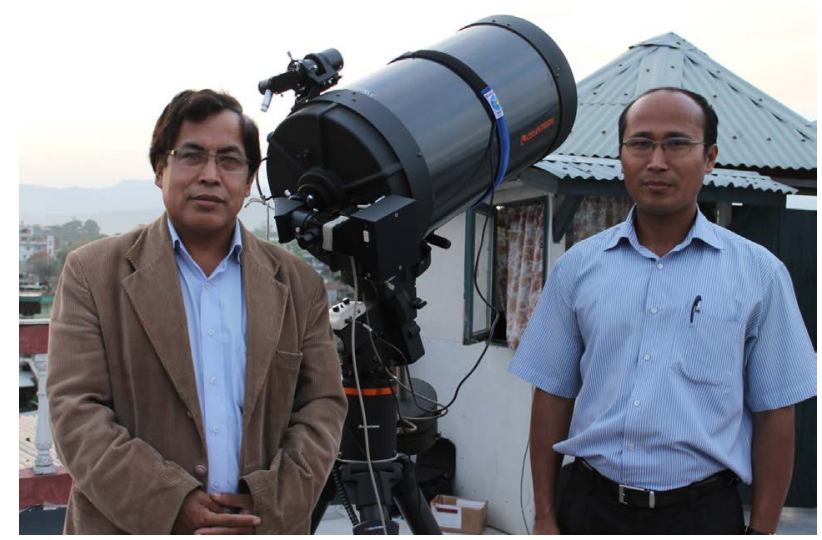

Figure 4. A photo snap of K. Y. Singh (left) \& I.A. Meitei (right) taken with Celestron CGE1400.

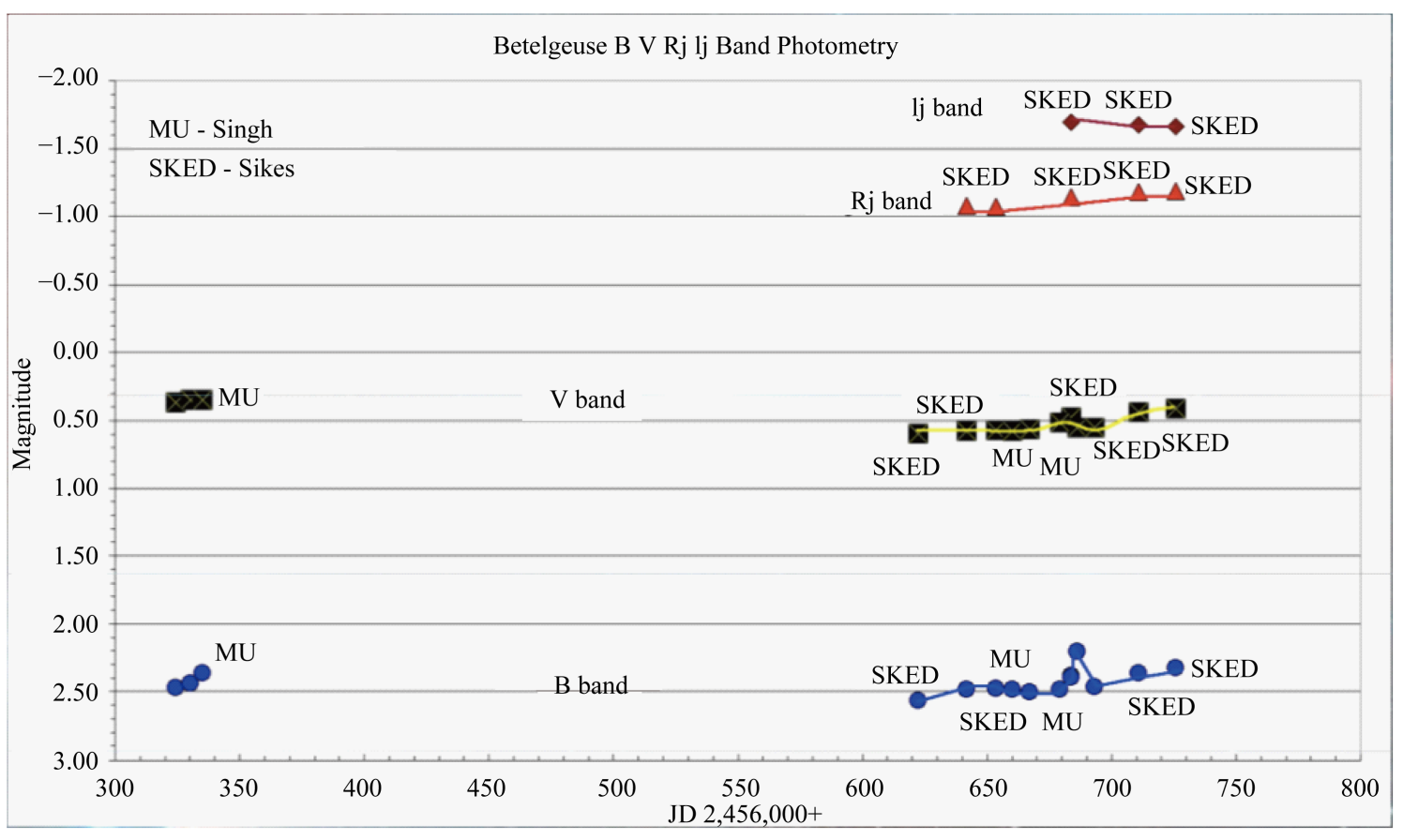

Figure 5. SSP-3 BVRI photometry of Betelgeuse. 


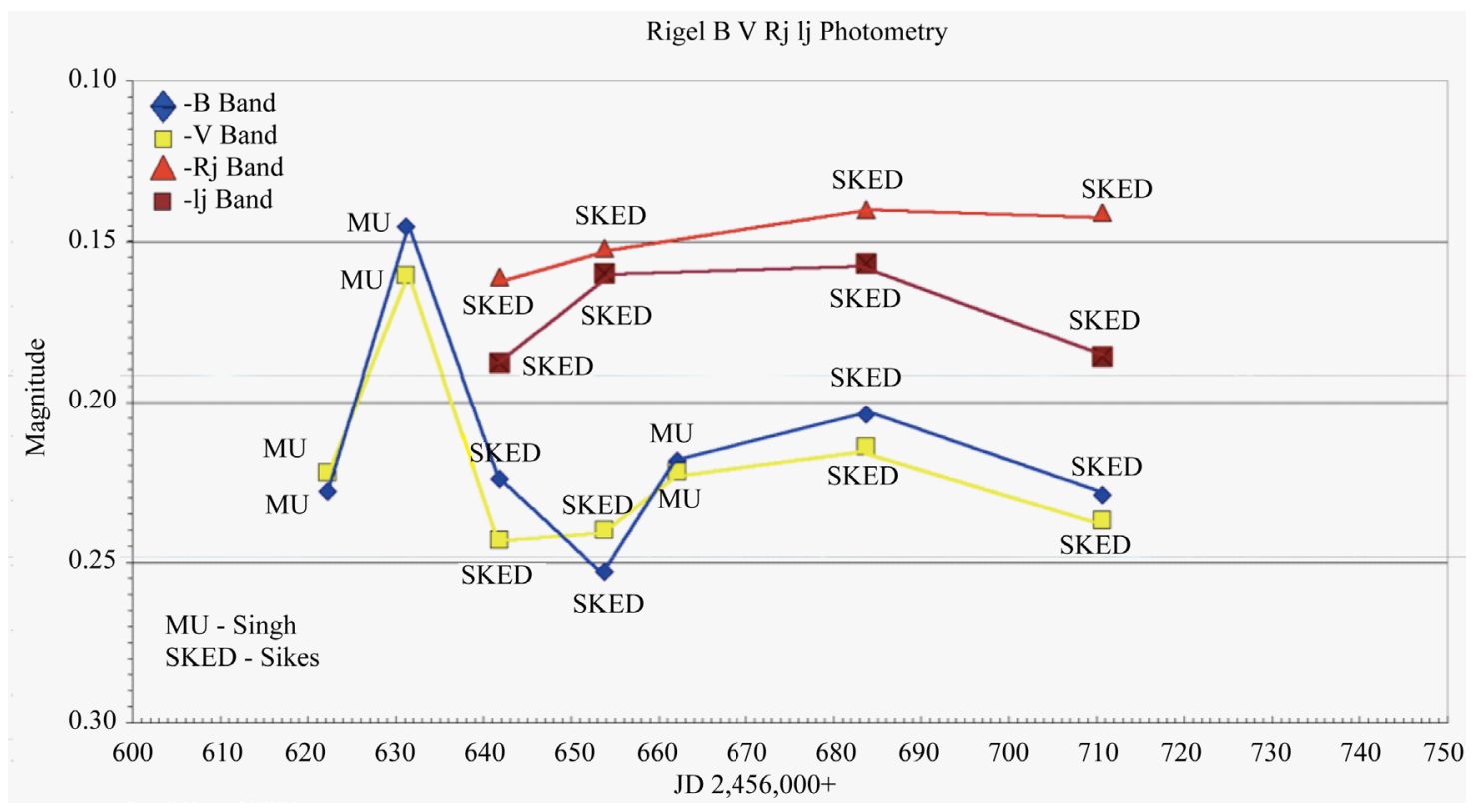

Figure 6. SSP-3 BVRI photometry of Rigel.

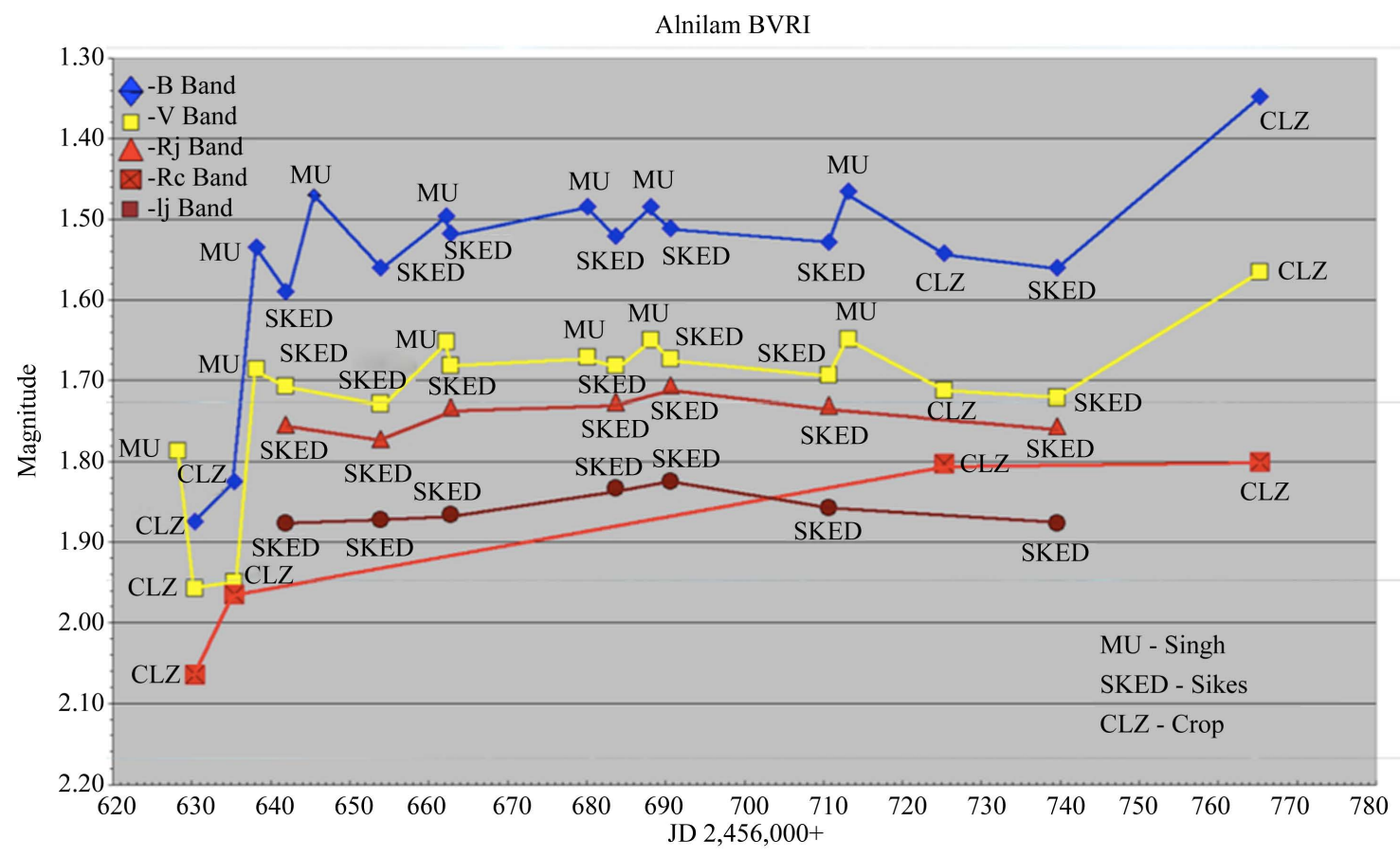

Figure 7. SSP-3 BVRI photometry of Alnilam.

participated in observation of the event. One Meade 12 inch telescope fitted with a Coronado SolarMax II 90 mm Hydrogen alpha filter and a DSLR Camera was used for observation of the transit. Photographs and video recordings were also taken with the help of a DSLR camera fitted to the telescope. Some photo snaps and a video recording of the observation of the Transit of Venus were published in the YouTube networks [6], [7]. A news report of the observation of the event is available at the network [8].

Figure 11 shows a photo snap of the Transit of Venus taken at 08:47:12 ISTon June 5, 2012.

Figure 12 and Figure 13 show two scenes where people including school children thronged at the observation site to observe the transit directly with their own eyes. 


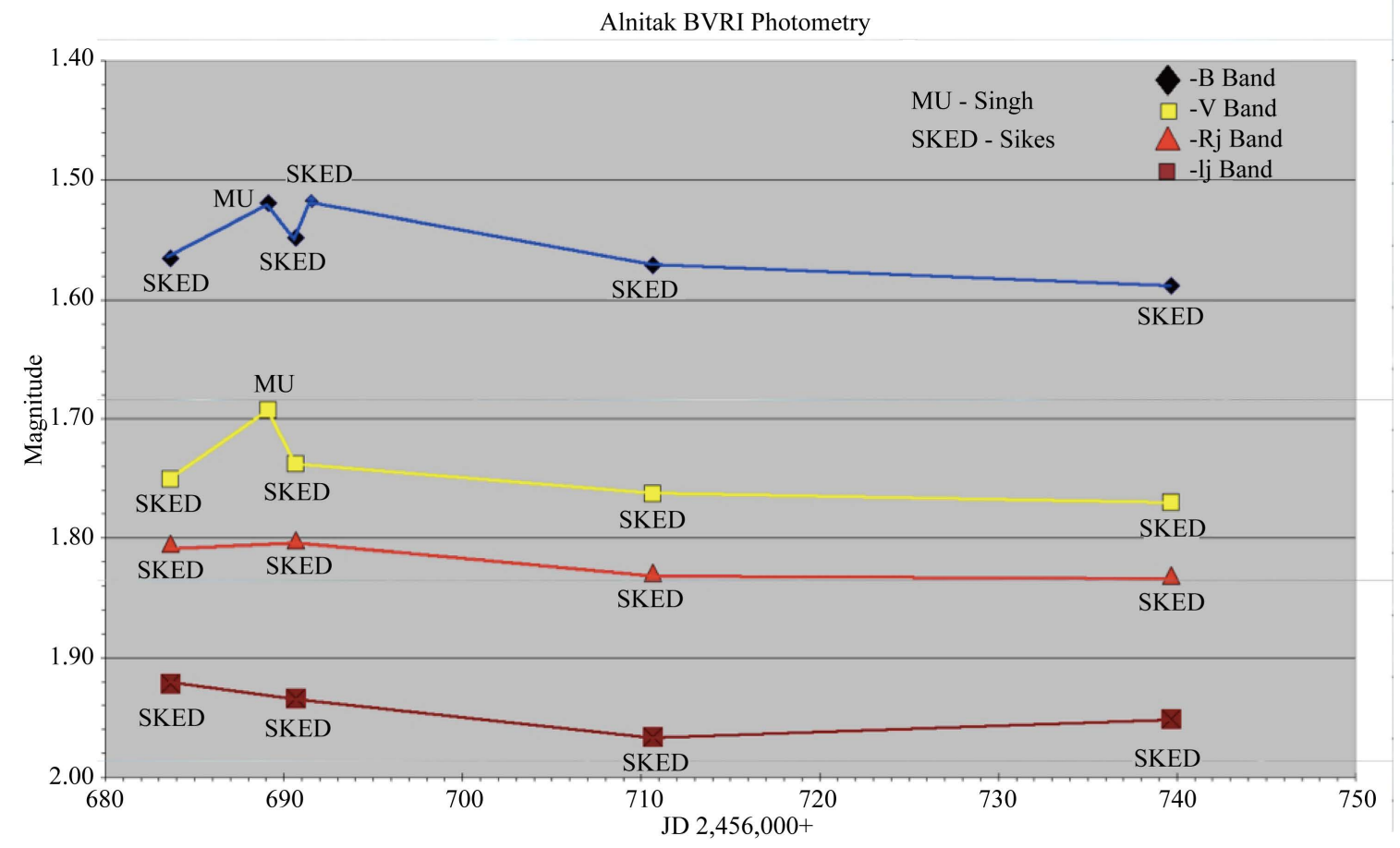

Figure 8. SSP-3 BVRI photometry of Alnitak.

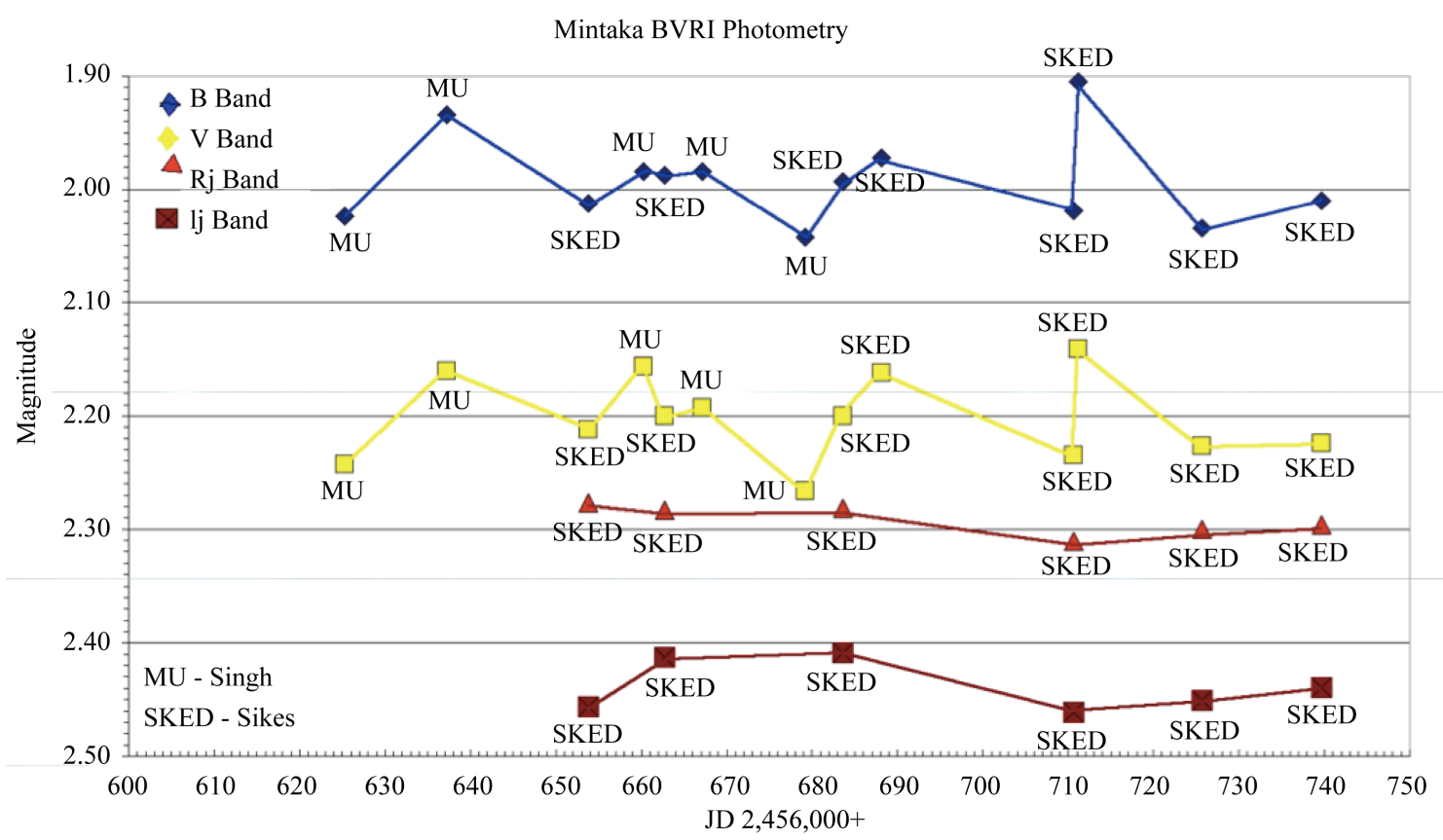

Figure 9. SSP-3 BVRI photometry of Mintaka.

One of the authors of this paper namely, K. Y. Singh has been playing a key role for growth of astronomy activities in Manipur University, where he is the lone faculty member teaching Astronomy, since 2009, in the Department of Physics of the University; he has strong enthusiasm and commitment for astronomy education. Under his cordinatorship, a number of seminars and workshops have been organized at Manipur University, the latest one being the 3-Day IUCAA sponsored “Introductory Workshop in Astronomy \& Astrophysics” which was held during February 10-12, 2014. The purpose of the latest workshop was to expose and motivate post- 


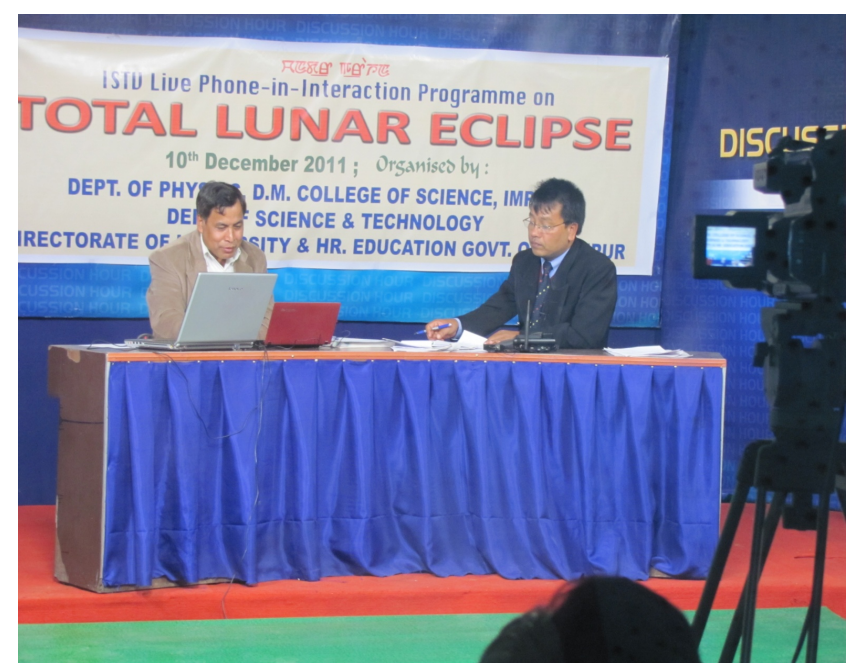

Figure 10. Live TV phone-in-interaction program of K.Y. Singh (left) with public regarding the total lunar eclipse on 10th Dec, 2011.

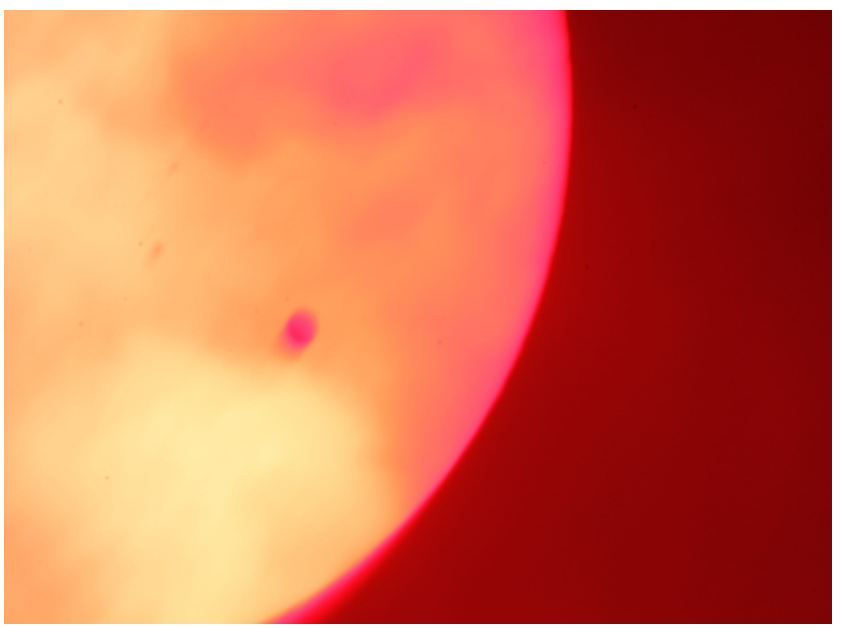

Figure 11. Position of Venus observed at 08:47:12 ISTon June 5, 2012; red spot seen on the sun disc is the shadow of Venus.

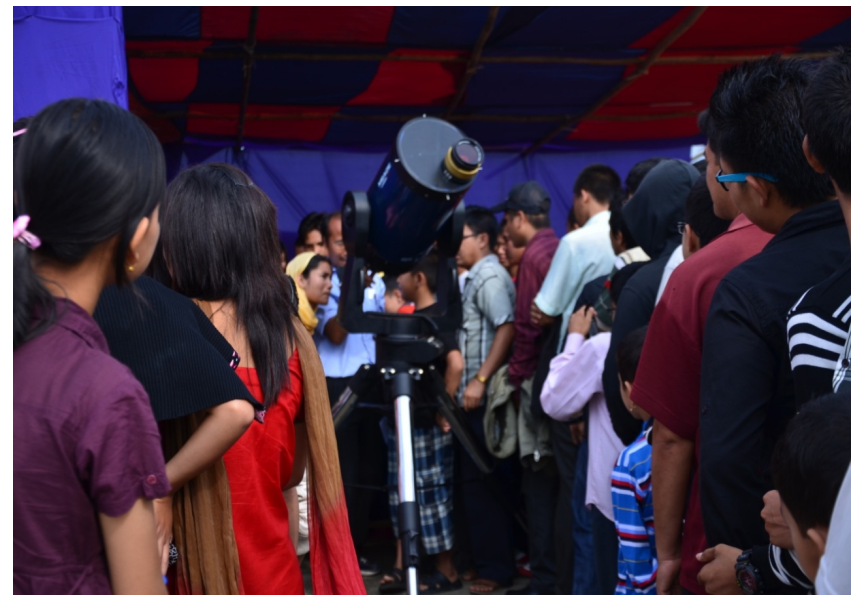

Figure 12. A scene where people were in queue for observing the transit of Venus on June 6, 2012. 


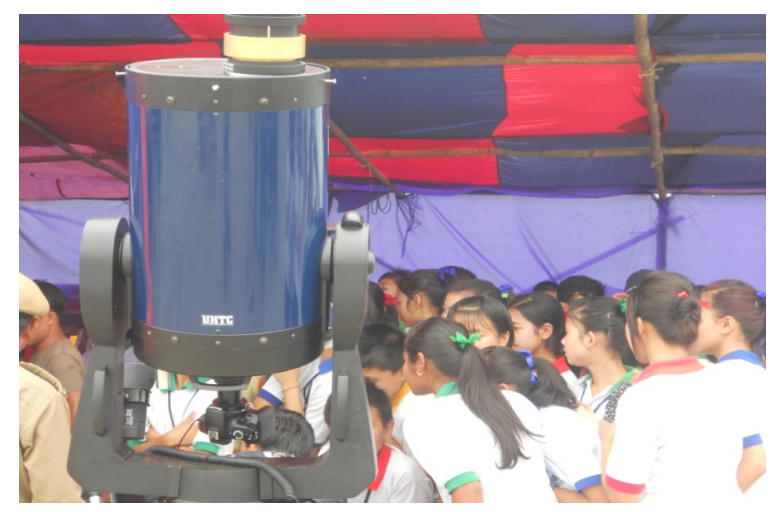

Figure 13. A scene where school children rushed to have a glimpse of the transit of Venus on June 6, 2012.

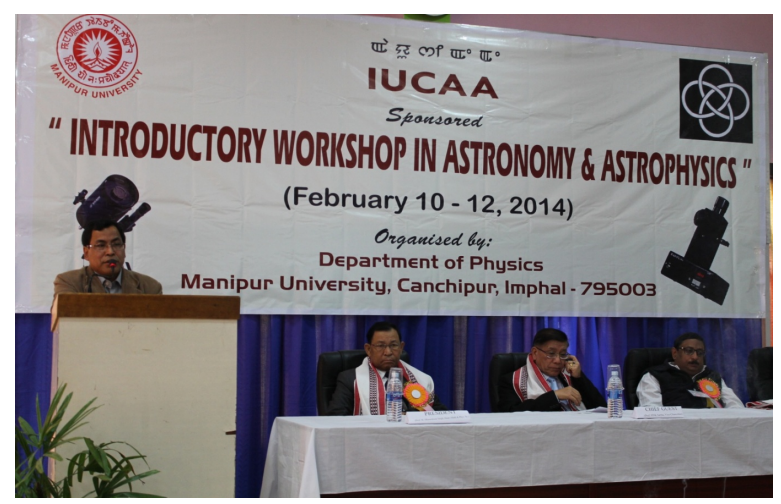

Figure 14. Inaugural function of a national workshop held at Manipur University, India during Feb 10-12, 2014.

graduate students, young researchers and college/university teachers towards Astronomy and Astrophysics. The workshop focused on observational astronomy based on small telescopes and its recent advances. A total of 37 participants from different parts of the country (India) participated in the workshop. Figure 14 shows a photo taken on the Inaugural Function of an IUCAA sponsored "Introductory Workshop in Astronomy \& Astrophysics" held at Manipur University, India during Feb 10-12, 2014 under coordinatorship of K. Y. Singh.

A report of the workshop was published in Khagol (A quarterly bulletin of the Inter-University Centre for Astronomy and Astrophysics (IUCAA), Pune, India) in its issue no. 98, April 2014 and is available at the web link [9]. Besides teaching Astronomy at the post-graduate level, implementing many government funded research projects, producing many Ph.D. degrees and presenting many invited talks in conferences, seminars and workshops, the astrophysics team led by K. Y. Singh has published a number of research papers in many international journals of repute, thereby reflecting fast growth of astronomy activities in Manipur, India.

\section{Conclusion}

We have innovatively designed and constructed three cost effective observatories of different models for housing small telescopes. These observatories can be used for scientific research and education and will be a good example to other researchers and institutions with limited budget. Using one of the observatories, we have been an active partner of the international "Orion Project" and have been producing SSP3 VBRI photometric data for the project. Using our observational facilities, we have done substantial works for popularization, education and research in astronomy in Manipur, a State in the northeast part of India. The presence of the observatories has brought fast growth of our astronomy activities with strong commitments.

\section{Acknowledgements}

S. Ajitkumar Singh is grateful to the Indian Space Research Organization, Department of Space, Government of 
India for providing him a JRF under a RESPOND Project.

\section{References}

[1] The Headquarter of the International Orion Project. http://www.hposoft.com/Orion/Orion.html

[2] Society for Astronomical Sciences, USA. http://www.socastrosci.org/symposium.html

[3] Observers of the Orion Project. http://www.hposoft.com/Orion/Observers.html

[4] Hopkins, J.I. (2014) Orion Project: A Photometry and Spectroscopy Project for Small Observatories. Proceedings for the 33rd Annual Conference of the Society for Astronomical Sciences: Symposium on Telescope Science, 12-14 June 2014, Ontario, 93-104.

[5] Sikes Observatory, Arizona, USA. http://www.hposoft.com/Orion/Observers/SO.html

[6] The Uploaded Photos of the Observation of the Transit of Venus on June 6, 2012, at Manipur University, India. http://www.youtube.com/watch?v=DJiTr4D3kLg

[7] The Uploaded Video of the Observation of the Transit of Venus on June 6, 2012, at Manipur University, India. http://www.youtube.com/watch?v=MztHnUIKZmM

[8] A News Report on the Observation of the Transit of Venus on June 6, 2012, at Manipur University, India. http://e-pao.net/GP.asp?src=17..070612.jun12

[9] (2014) Khagol Published by IUCAA, Pune, India. Issue No. 98, 7. http://ojs.iucaa.ernet.in/index.php/khagol/article/view/159/142 
Scientific Research Publishing (SCIRP) is one of the largest Open Access journal publishers. It is currently publishing more than 200 open access, online, peer-reviewed journals covering a wide range of academic disciplines. SCIRP serves the worldwide academic communities and contributes to the progress and application of science with its publication.

Other selected journals from SCIRP are listed as below. Submit your manuscript to us via either submit@scirp.org or Online Submission Portal.
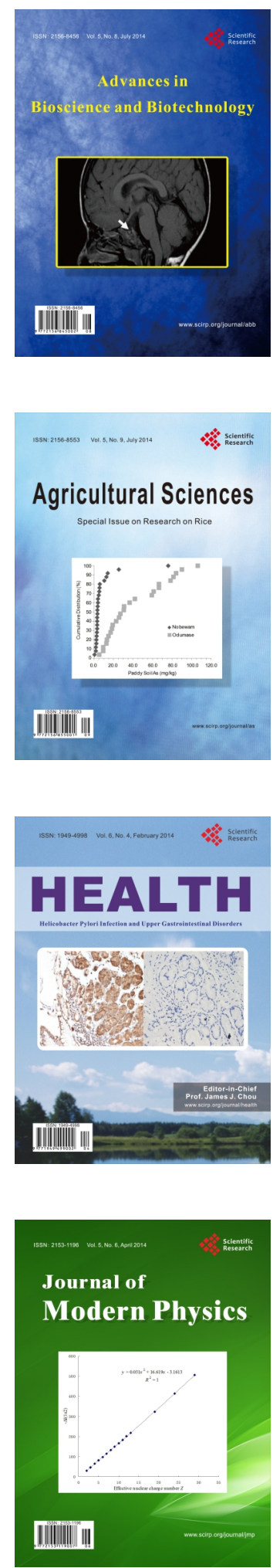
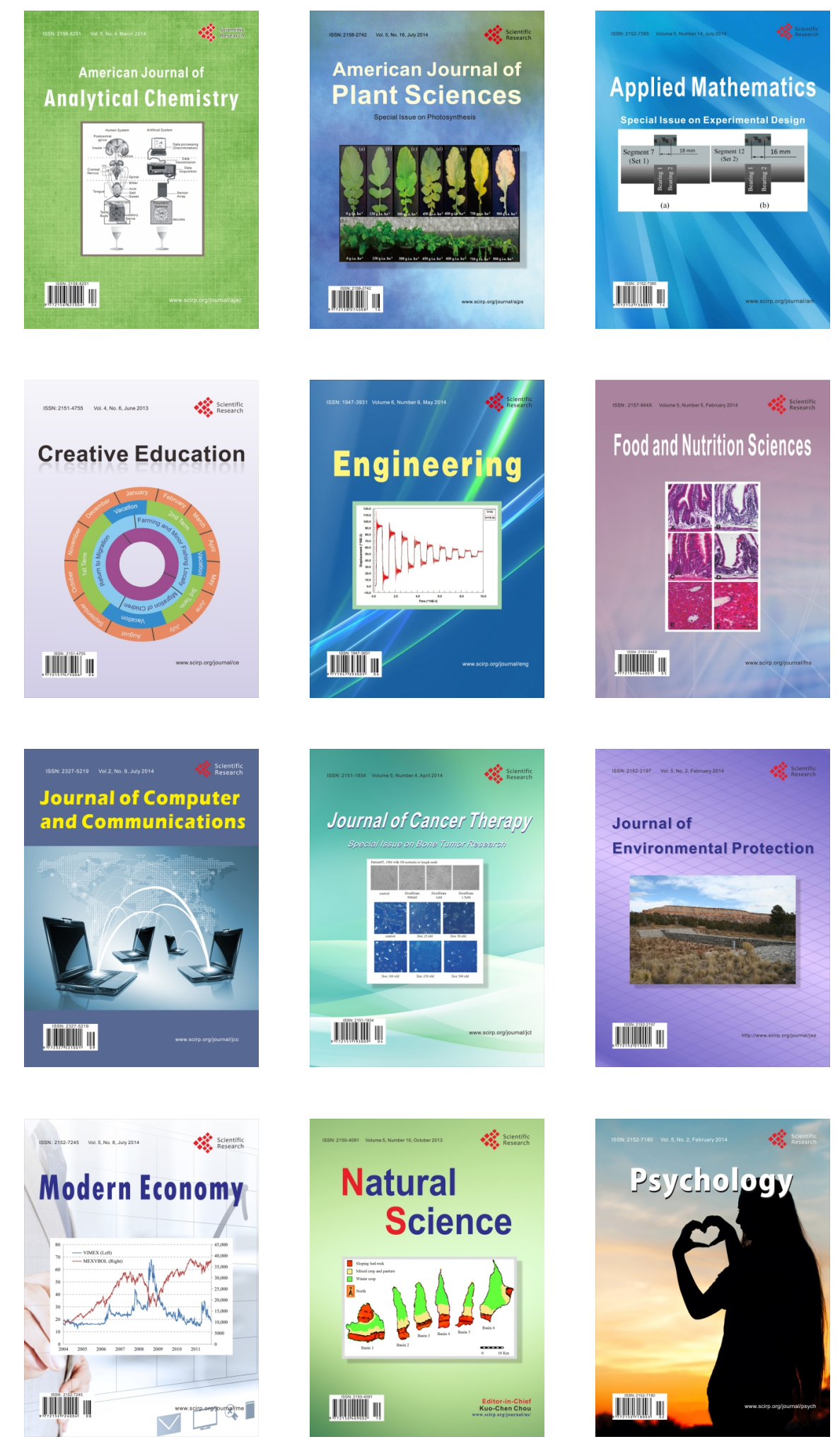